\title{
SITUATIONAL EFFICIENCY PARAMETERS OF SUCCESSFUL AND UNSUCCESSFUL ICE HOCKEY TEAMS AT IIHF WORLD CHAMPIONSHIP DIVISION I B
}

\author{
Alan Franjković, Bojan Matković, Dragan Milanović \\ University of Zagreb, Zagreb, Croatia
}

\begin{abstract}
Background. Performance indicators, which consist of a selection or combination of action variables, can be used to define performance in invasion games. These performance indicators should relate to successful performance. The same principles of match analysis can be used in all invasive games, and typical performance indicators can also be easily translated from one sport to another. The purpose of this study was to determine differences in situational efficiency parameters that differentiate ice hockey teams according to outcome. Sample of entities consisted of 15 games played on IIHF World Championship Division I B.

Methods. Situational efficiency variables that affected final outcome were comprised of 11 parameters. Differences between successful and unsuccessful teams were detected using Mann-Whitney $U$-test for nonparametric variables. Significant value was set at $p \leq .05$.

Results. Results showed overall statistical differences in situational parameters between winner and defeated teams. The best variables that differed teams were assists and shots on goal $(Z=3.94, p>.000$ and $Z=-3.40$, $p>.001)$, while on the other hand saves by goalie $(\mathrm{Z}=3.26, p>.001)$ represented defeated teams.

Conclusion. On the basis of obtained results we suggest that winning teams had greater team play which leads to better passing play and shooting on goal.
\end{abstract}

Keywords: team sport, notational analysis, final outcome.

\section{INTRODUCTION}

Ice hockey is very intense, intermittent and the fastest team sport that requires a wide variety of motor skills as well as high level of fitness to compete at elite level (Quinney, 2005). By the games classification, Read and Edwards (1992) introduced three game categories: net and wall games, invasion games and striking/fielding games. The invasive games can further be divided into goal throwing, try scoring and goal striking games. As well as soccer, ice hockey is a typical goal striking game, too. Performance indicators, which consist of a selection or combination of action variables, can be used to define performance in invasion games. These performance indicators should relate to successful performance. The same principles of match analysis can be used in all invasive games, and typical performance indicators can also be easily translated from one sport to another. Based on previous research, some factors, such as passing, tackling, shots, goals, time in possession, field position, set pieces contributing to success or improved performance in invasive games, can be introduced. (Huhhes \& Bartlett, 2002).

Within the game, players' quality, teamwork and tactics primary determine the team's efficiency and competitive success (Trninić et al., 2000). By analyzing situational efficiency indicators it is possible to derive model values of team efficiency and individual player performance in defense and offense, as well as a comparison of players and teams, which is important for more efficient programming of the preparation process (Milanović, 1997). 
Situational parameters become one of the most important and objective factors determining overall efficiency in the game, especially in team sports. Hunter and O'Donoghue (2001) compared successful and unsuccessful rugby teams in 1999 World Cup. Their study found two of eleven variables related to winning teams.

In his research, Thomas (2006) analysed the Harvard ice hockey team and made the argument that hockey could be described as a continuous time semi-Markov process. Thomas separated the game of ice hockey into 19 distinct states including: offensive team with the puck in defensive zone, defensive team with the puck in the offensive zone, faceoff at center ice, defensive takeaway, among others.

Moskowitz and Wertheim (2012) disagreed with that statement. They studied multiple sports, including hockey, and tried to determine if teams who were ranked as a top defensive team won championships more often than those who were ranked as a top offensive team. In every sport they tried to establish if there were just as many offensive teams winning as there were defensive teams winning.

Molik et al. (2012) found significant differences between disability groups in the anthropometric measures of training equency, height, and sledge length, but there was no strong evidence to support disability group differences in game efficiency parameters. The results may confirm the lack of a need for classification in sledge hockey or they may be evidence that a classification system is needed as the lower functioning disabilities are not being represented in the sport.

Given the diversity of invasion team sports, many assessment tools have been developed in an attempt to measure aptitude to, or performance in, a variety of team sports. Nadeau, Godbout, and Richard (2008) modified Team Sport Assessment Procedure (TSAP) for ice hockey. It consists of 10 explained constants that three well educated specialists need to mark. These constants made it possible to avoid unreasonable distortions of efficiency index values due to low numbers of ball or puck losses (Grehaigne, Godbout, \& Bouthier, 1997; Nadeau et al., 2008).

Nowadays, best efficiency parameters are given by NHL and KHL statistics. They go in deep spheres of hockey so that you can get information about time spent on the ice, how many shoots the player performed in attacking situations, how many hits, blocks, penalties there were in defensive situations.

The standard situational efficiency indicators used in this study provided a precise quality description of the team play. The aim of this study was to determine which situational parameters differed between winning and defeated teams in Ice Hockey World Championship Division IB. We anticipate significant differences in some situational parameters between winning and defeated teams. We considered scored goals in each period and their difference, number of assists, minutes of penalty, total time playing power play, total time playing shorthanded, face-offs won and lost, total shots on goal and saves.

\section{METHODS}

Subjects. The study was conducted on the sample of 6 hockey teams (15 games, 30 opponents) playing in the 2016 IIHF World Championship Division I B. Teams were Croatia, Estonia, Great Britain, Lithuania, Romania and Ukraine.

Variables. The variables that represent situational efficiency comprised 11 standard indicators in ice hockey game. These indicators were standardized by the International Ice Hockey Federation (IIHF). All results were downloaded from official IIHF website.

Variables Scored Goals in $1^{\text {st }}$ Period.(GOL_1P) Scored Goals in $2^{\text {nd }}$ Period (GOL_2P) and Scored Goals in $3^{\text {rd }}$ Period (GOL_3P) represent scored goals in period by each team. There is a slight difference between periods. Variable Assist represents number of assists as a result of good teamwork and usually leads to good opportunities to score, goal. Teams that have lots of assists besides scoring show excellent teamwork. Variable Points shows relations between scored goals and teamwork. More individual plays make points even to scored goals and more teamwork makes points tree times larger than scored goals. Variable Penalty Minutes (PIM) represent minutes of penalty that team gets for violating the rules. That leads to play shorthanded or play with man (or two men) advantage (Power play). Variable Power Play Time (PPT) represents total time that team plays power play. There can be huge differences between obtained penalties and served penalties (10, 20 and $25 \mathrm{~min}$ (misconduct and match penalties) if penalty does not count or obtained penalty at the end of last period). Variable Power Play Goals (PPG) represents goals scored with man advantage. It is a very good indicator of 
team play. Variables Face-off $+(\mathrm{FO}+)$ and Faceoff-(FO-) represent a get or loose puck position on face-offs. Variable Shots on Goal (SOG) represents shots that it has been saved by goalie or scored. Variable Saves by Goalie (SVS) represents number of saves that goalie makes. It does not count shots that hit the post or miss goal frame. Variable Win/ Loose (W(1)/L(0)) represents discriminant variable that differs winning and losing teams in the game.

Table 1. Description of variables

\begin{tabular}{|c|c|}
\hline GOL_1P & Scored goals 1. period \\
\hline GOL_2P & Scored goals 2. period \\
\hline GOL_3P & Scored goals 3. period \\
\hline ASSIST & Number of assists \\
\hline POINTS & Number of points \\
\hline PIM & Penalty minutes \\
\hline PPT & Power play time \\
\hline PPG & Power play goals \\
\hline FO+ & face-off + \\
\hline FO- & face-off - \\
\hline SOG & Shots on goal \\
\hline SVS & Saves by goalie \\
\hline W(1)/L $(0)$ & Discrimination Var Win/Loose \\
\hline
\end{tabular}

Data analysis. Data was analyzed using Statistica 12.0 software for Windows. For all parameters, arithmetic mean and standard deviation were calculated. Kolmogorov-Smirnov test was used to determine whether the variables were normally distributed ( $\max D$ and $p$ value). Group differences between variables were analyzed using Man-Whitney $U$-test. To determine parameters which differentiated teams according outcome, discriminant analysis was performed.

\section{RESULTS}

Most of the variables in sport are binominal. Thomas (2007) and Ryder (2014) suggest that goal scoring in hockey follows a Poisson distribution. This results in looking at competing Poisson processes when trying to predict the outcome of the games. Ryder (2014) shows that by breaking down the scoring in hockey into short time intervals, one can accurately predict goals, except in the last two minutes when scoring is greatly increased due to the occasional strategy of pulling the goalie for an extra attacker when a team is down by one or two goals.

Goals scored in each period differ in the second period and that tells us that the second period was critical for winning/defeated teams. Some teams had scored to 6 goals in that period to gain advantage in result. So, from this point of view, the second period is the most important for coaches to prepare their teams. Assist for winning teams represent good passing game, which leads to better team game. PIM of $13.00 \pm 8.73$ shows rather aggressive play by winning teams. PPG of $1.13 \pm 10.6$ and PPT of $7.33 \pm 3.51$ minutes did not have such influence on the final result. In consideration of won and lost face-off, it does not have statistical difference and influence on gaining puck possession and start of attack. SOG was rather high and that was probably

Table 2. Basic descriptive situational efficiency parameters of winning teams

\begin{tabular}{|c|c|c|c|c|c|c|c|}
\hline \multirow{2}{*}{ Predictors } & \multirow{2}{*}{$\mathbf{N}$} & \multicolumn{6}{|c|}{ Winning teams } \\
\hline & & & $S D$ & Min & Max & $\max D$ & $p$-value \\
\hline GOL_1P & 15 & 1.47 & 0.92 & 0 & 3 & 0.33 & $p<.10$ \\
\hline GOL_2P & 15 & 2.07 & 1.71 & 0 & 6 & 0.18 & $p>.20$ \\
\hline GOL_3P & 15 & 1.47 & 1.46 & 0 & 5 & 0.18 & $p>.20$ \\
\hline ASSIST & 15 & 7.53 & 3.76 & 2 & 16 & 0.12 & $p>.20$ \\
\hline PIM & 15 & 13.00 & 8.73 & 4 & 35 & 0.19 & $p>.20$ \\
\hline PPG & 15 & 1.13 & 1.06 & 0 & 3 & 0.22 & $p>.20$ \\
\hline PPT & 15 & 7.33 & 3.51 & 2.26 & 16.00 & 0.15 & $p>.20$ \\
\hline $\mathrm{FO}+$ & 15 & 35.20 & 8.60 & 22 & 52 & 0.15 & $p>.20$ \\
\hline FO- & 15 & 30.33 & 7.62 & 19 & 46 & 0.16 & $p>.20$ \\
\hline SOG & 15 & 36.33 & 8.92 & 23 & 58 & 0.16 & $p>.20$ \\
\hline SVS & 15 & 21.07 & 7.16 & 10 & 32 & 0.15 & $p>.20$ \\
\hline \multicolumn{6}{|c|}{ Critical $D$} & \multicolumn{2}{|l|}{0.304} \\
\hline
\end{tabular}


the result of good passing and team play showed by assist. As we see, results in Table 2 showed that variable GOL_1P did not have normal distribution by the K-S test criteria.

Results in Table 3 showed that defeated teams on the other hand had low scoring by each period of play. With low scoring, variable Assist cannot be high. In comparison to winning teams, they all had the same PPT $(7.12 \pm 2.65)$, but defeated teams did not score so much PPG $(0.33 \pm 0.49)$ that will help them in the final result. Like we mentioned earlier, face-off did not statistically differ between winning and defeated teams. Defeated teams had $23.13 \pm 8.11$ shots on goal. With high percentage of saves and not so many shots on net, goalies can easily accomplish their goals.
Kolmogorov-Smirnov test show that variables GOL_2P, GOL_3P, ASSISIT and PPG were not normally distributed. In that manner we cannot use $t$-test for independent samples, so we used Mann Whitney test to identify differences between winners and defeated teams.

Results in Table 4 show descriptive parameters of analyzed situational variables. Presenting results, winning teams scored more goals in each period, had more Assists, Power Play Goals and Shots on Goal. The only thing that defeated teams had better is number of Saves by Goalie. Both teams had almost the same power play time, but better teams had statistically greater PPG.

Teams differ at most in Assist during the game. The more goals the team scores, the more assists

\begin{tabular}{|l|c|c|c|c|c|c|c|}
\hline \multirow{2}{*}{ Predictors } & \multirow{2}{*}{$\mathbf{N}$} & \multicolumn{6}{c|}{ Defeated teams } \\
\cline { 3 - 8 } & & & $S D$ & Min & Max & $\max D$ & $p$-value \\
\hline GOL_1P & 15 & 0.60 & 0.63 & 0 & 2 & 0.29 & $p<.15$ \\
\hline GOL_2P & 15 & 0.53 & 0.64 & 0 & 2 & 0.33 & $p<.10$ \\
\hline GOL_3P & 15 & 0.33 & 0.62 & 0 & 2 & 0.44 & $p<.01$ \\
\hline ASSIST & 15 & 2.07 & 2.09 & 0 & 8 & 0.31 & $p<.10$ \\
\hline PIM & 15 & 15.87 & 14.94 & 4 & 60 & 0.23 & $p>.20$ \\
\hline PPG & 15 & 0.33 & 0.49 & 0 & 1 & 0.42 & $p<.01$ \\
\hline PPT & 15 & 7.12 & 2.65 & 2 & 13 & 0.26 & $p>.20$ \\
\hline FO+ & 15 & 30.33 & 7.62 & 19 & 46 & 0.16 & $p>.20$ \\
\hline FO- & 15 & 35.20 & 8.60 & 22 & 52 & 0.15 & $p>.20$ \\
\hline SOG & 15 & 23.13 & 8.11 & 10 & 33 & 0.22 & $p>.20$ \\
\hline SVS & 15 & 31.40 & 7.44 & 21 & 52 & 0.20 & $p>.20$ \\
\hline & & & & Critical $D$ & 0.304 & \\
\hline
\end{tabular}

Table 3. Basic descriptive situational efficiency parameters of defeated teams

\begin{tabular}{|l|c|c|c|c|c|}
\hline \multicolumn{1}{|c|}{ Predictors } & $\mathbf{N}$ & Win 0 & Def 0 & $\mathbf{Z}$ & $p^{*}$ \\
\hline GOL_1P & 15 & $1.47 \pm 0.92$ & $0.60 \pm 0.63$ & -2.49 & .013 \\
\hline GOL_2P & 15 & $2.07 \pm 2.07$ & $0.53 \pm 0.64$ & -2.70 & .007 \\
\hline GOL_3P & 15 & $1.47 \pm 1.46$ & $0.33 \pm 0.62$ & -2.28 & .023 \\
\hline ASSIST & 15 & $7.53 \pm 3.76$ & $2.07 \pm 2.09$ & -3.94 & .000 \\
\hline PIM & 15 & $13.0 \pm 8.73$ & $15.87 \pm 14.94$ & 0.17 & .868 \\
\hline PPG & 15 & $1.13 \pm 1.06$ & $0.33 \pm 0.49$ & -2.05 & .040 \\
\hline PPT & 15 & $7.33 \pm 3.51$ & $7.12 \pm 2.65$ & -0.25 & .803 \\
\hline FO+ & 15 & $35.20 \pm 8.60$ & $30.33 \pm 7.62$ & -1.27 & .206 \\
\hline FO- & 15 & $30.33 \pm 7.62$ & $35.20 \pm 8.60$ & 1.27 & .206 \\
\hline SOG & 15 & $36.33 \pm 8.92$ & $23.13 \pm 8.11$ & -3.40 & .001 \\
\hline SVS & 15 & $21.07 \pm 7.16$ & $31.40 \pm 7.44$ & 3.26 & .001 \\
\hline
\end{tabular}

Table 4. Differences between winning and defeated teams (Mann-Whitney test results) 
can they get, but only if they have good team play. Next parameter that the teams differ in is SOG. It is normal that the more shots you take, the more likely will you score more goals. In this case winning teams had $36.33 \pm 8.92$ against defeated teams $23.13 \pm 8.11$. It is more than 10 shots per game and it is easy to expect more goals scored.

The only thing that defeated teams had was SVS. It is normal for the team that it takes more shots on goal, and goalies have to save more. If goalies have problems to save shots, it results in a greater score difference. In that kind of situation we must take into consideration the save percentage, so that we can get a picture of a goalie performance.

Teams did not statistically differ in faceoffs. Liardi and Carron (2011) found that face-off success was not related to home team wins ( $p>$ $.05)$. All the results of face-offs were around $50 \%$.

\section{DISCUSSION}

The aim of this study was to determine a group of significant situational parameters that differentiated winning and losing teams on Ice Hockey World Championship Division IB in Zagreb. Results in Table 4 showed that statistical differences between winning and defeated teams were establish in goals scored, assists, Power Play Goals, Shots on goal and Saves by Goalie when significance was set at .05 .

Many studies in performance analysis compare the collective results of two or more randomly selected winning or losing teams. This is done in order to try to identify performance features that distinguish winning and losing sides. This type of study tries to find general rules for a particular sport, e.g. the long ball game is not as effective as a passing game in soccer. However, Jones (2008) suggests that combining results in this way may mask any individual team performance and that can then mean that inherent weaknesses and strengths of individual teams may not be identified. In effect combining the performance of lots of teams may produce a general pattern that does not actually hold true for any team.

According to Roith and Magel (2014), goals against have a larger magnitude than goals scored. This would lead us to believe that it is more important for the team that is striving to make the postseason to keep their opponents from scoring an abundance of goals.
Presented results showed that the biggest differences were in assists. This means that winning teams had better team play that resulted in better passing play to more shots on goal and scoring chances. On the other hand, defeated teams had more saves, and final result depended on the quality of goalkeeping and how many goals the goalie could not save.

Also, winning teams differed in scoring goals in each period. The first period represented motivation at the start of a match. The second period represented plays on tactics showed in the first period, and the third period represented team's conditioning fitness (level of endurance). Statistical analysis shows that a very important part of a game is the second period in which the teams that score more have greater probability to win the game.

Some teams try to focus more on face-offs. According to Liardi and Carron (2011), the home team wins $3.01 \%$ more games when it achieves greater than $50 \%$ for the face-offs. On the other hand, the team must have more face-offs won in offensive zone that leads to advantage on shots on goal. In this study, winning teams didn't have significantly more face-offs than defeated teams.

Power Play Goals had also statistical significance, but that did not make such difference between teams. On team statistics, teams that had the biggest percentage of Power Play ended on $4^{\text {th }}$ and $5^{\text {th }}$ place. It is good that teams have better special team play (power play, penalty kill), but it is better to have developed penalty kill to get fewer goals.

This kind of data did not show us deeply what was going on the ice. Some of mistakes are covered by better tactics or by good saves by goalie. For better information we must use notational analysis that is an objective way of recording performance, so that critical events in that performance can be quantified in a consistent and reliable manner (Milanović, Jukić, Vuleta, Gregov, \& Sporiš, 2008). The use of systematic observation instruments provides researchers with a method of collecting behavioral data on both the coach and the athlete. These data can be analyzed and processed in a variety of ways to provide a descriptive profile that can be used for giving both the athlete and the coach feedback about their actions. This implies that without feedback there will be no change in performance. The athlete will have no idea that there is an alternative or a better way. However, 
it has been identified that coaches are only able to recall $30-50 \%$ of key performance factors they witnessed, even with special training in observation (Franks \& Miller, 1991)

Hughes and Franks (2004) indicated 4 main usages of notational analysis: analysis of movement, technical analysis, tactical analysis and development of database and modeling. Sports biomechanics is concerned with fine detail about individual sports techniques in comparison to notational analysis which is more concerned with gross movements or movement patterns in games or teams. Furthermore, notational analysts are typically more concerned with strategic and tactical issues in sport than with technique analysis. However, both emphasize the development of systematic techniques of observation and have 'key events' as important features of their theoretical foundations.

In Lee's (2011) study, players' atitudes towards video showed that using video analysis was surprisingly positive. Players seemed to be quite responsive to using video analysis for player development, and its use with special teams, the same as the coaches. The younger players seemed to want to use video analysis for all aspects of the game, which is a positive sign but cannot always be a wise thing. With the older players it is seen that the use of video is not a major focus in the individual game preparation, but serves as a team viewing resource. The higher the level, the less the athlete needs to see when it comes to the basic things such as player development skills, skating and " 1 on 1" and " 2 on 1". The video time is set to go over systems, power play, penalty kill, special teams and faceoff plays. In rare cases a player or a coach would want to focus on an individual effort.
Advances in both computer and video technology can make this observation process more efficient and also provide the coach with audio-visual feedback about their interactions with athletes. The next phase of solving these problems in their entirety is translating the use of these objective observation systems into practice.

\section{CONCLUSION}

Our results indicate that that winning and defeated teams differed in situational efficiency parameters at the world championship. Teams differed the most in Assists and Shots on Goal (more probability of scoring). This tells us that coaches need more to prepare their teams mentally to play better team play that will lead to more scoring chances. Ice hockey consists of very complex technical-tactical structures, whereby you need to gain advance over the opponent. For more precise situational parameters it would be good to observe passing game and lost pucks (unforced), turnovers, rebounds, shots taken, blocked shots. All of those data can be found in NHL statistic. Therefore, in the future it will be recommended that teams have a specialized person for notational analysis. Notational analysis is used by coaches and sport scientists to gather objective data on gross movements or movement patterns in games or teams the performance of athletes (Bartlet, 2001). Tactics, technique, individual athlete movement and workrate can all be analyzed, enabling coaches and athletes to learn more about performance and gain a competitive advantage. Systems for notational analysis are becoming increasingly sophisticated, reflecting the demands of coaches and scientists, as well as improvements in technology.

\section{REFERENCES}

Bartlet, R. (2001). Performance analysis: Can bringing together biomechanics and notational analysis benefit coaches? International Journal of Performance Analysis in Sport, 1, 122-126.

Franks, I., \& Miller, G. (1991). Training Coaches to Observe and Remember. Journal of Sports Sciences, 9(3), 285-297.

Garcia, J., Ibanez, S. J., De Santos, R. M., Leite, N., \& Sampaio, J. (2013). Indentifying basketball performance indicators in regular season and playoff games. Journal of Human Kinetics, 36, 161-168. https://dx.doi. org/10.2478\%2Fhukin-2013-0016
Grehaigne, J. F., Godbout, P., \& Bouthier, D. (1997). Performance assessment in team sports. Journal of Teaching in Physical Education, 16, 500-516.

Hughes, M. \& Franks, I. M. (2004). Notational analysis of sport: Systems for better coaching and performance and sport. London: Routlege.

Huhhes, M. D., \& Bartlett, R. M. (2002). The use of performance indicators in performance analysis. Journal of Sports Sciences, 20(10), 739-754. https://doi. org/10.1080/026404102320675602

Hunter, P., \& O'Donoghue, P. (2001). A match analysis of the 1999 Rugby Union World Cup. In M. F. Hughes, 
Book of Abstracts Fifth World Congress of performance analysis in sports (pp. 95-90). Cardiff: UWIC.

IIHF. (2016). International Ice Hockey Federation. Retrieved from http://www.iihfworlds2016.com/

James, N., Jones, N. M. P., \& Mellalieu, S. D. (2005). The development of position - specific performance indicators in professional rugby union. Journal of Sport Sciences, 23(1), 63-72. https://doi.org/10.1080/026404 10410001730106

Jones, N. J. (2008). An Objective Method for Depicting Team Performance in Elite Professional Rugby Union. Journal of Sport Sciences, 26(7), 691-700. http://dx.doi. org/10.1080/02640410701815170

Lee, M. (2011). The use of video feedback as a performance analysis coaching tool in amateur level ice hockey (Unpublished Bachelors Thesis). Vierumaki: Haaga-Helia University of Applied Sciences.

Liardi V. L., \& Carron A. V. (2011). An analysis of National Hockey League face-offs: Implications for the home advantage. International Journal of Sport and Exercise Psychology, 9(2), 102-106.

Milanović, D. (1997). Fundamentals of sport trainig. In D. Milanović, Handbook for sport coaches. Zagreb: Faculty for Physical Education.

Milanović, D., Jukić, I., Vuleta, D., Gregov, C., \& Sporiš, G. (2008). Performance analysis in sport games - methodological approach. Performance analysis in sport games - methodological approach (pp. 37-48). Magdeburg: Otto-von-Guericke-Universität Magdeburg.
Molik, B., Morgulec-Adamowicz, N., Kosmol, A., Yilla, A. B., Filipkovska, A., Lewandowski, M., ... Herink, R. (2012). Game performance in ice sledge hockey: An Exploratory examination into type of disability and anthropometric parameters. Clinical Journal of Sports Medicine, 22(1), 65-69. https://doi. org/10.1097/JSM.0b013e3182420677

Moskowitz, T., \& Wertheim, J. L. (2012). Scorecasting: The Hidden Influences Behind How Sports Are Played and Games Are Won. New York: Tree River Press.

Nadeau, L., Godbout, P., \& Richard J. F. (2008). Assessment of ice hockey performance in real-game conditions. European Journal of Sport Science, 8(6), 379388. http://dx.doi.org/10.1080/17461390802284456

Quinney, H. (2005). Sport on ice. In T. S. Reilly, Phisiology of Sports (pp. 275-296). Taylor \& Francis.

Read, B., \& Edwards, P. (1992). Teaching Children to Play Games. Leeds: White Line Publishing.

Roith, J., \& Magel, R. (2014). An analysis of factors contributing to wins in the National Hockey League. International Journal of Sports Science, 4(3), 84-90. doi: 10.5923/j.sports.20140403.02

Ryder, A. (2004). Poisson Toolbox: A rewiew of the Poisson Probability Distribution in hockey. Retrieved from Hockey Analitcs: http://www.hockeyanalytics.com

Thomas, A. C. (2006). The impact of puck possession and location on ice hockey strategy. Journal of Quantitative Analysis in Sports, 2(1).

Trninić, S., Dizdar, D., \& Dežman, B. (2000). Empirical verification of veighted system of criteria. Collegium Antropologicum, 24(2), 443-465. 